\title{
Comunicação do enfermeiro no cuidado ao parto: ótica de mulheres surdas
}

\author{
Communication of nurses in childbirth care: the view of deaf women \\ Comunicación del enfermero en el cuidado al parto: percepción de mujeres sordas
}

Recebido: 05/03/2021 | Revisado: 11/03/2021 | Aceito: 14/03/2021 | Publicado: 21/03/2021

\author{
Denise Elen Costa Reis \\ ORCID: https://orcid.org/0000-0001-7901-3661 \\ Universidade Estadual do Sudoeste da Bahia, Brasil \\ E-mail: deniseereis@gmail.com \\ Émile Assis Miranda Oliveira \\ ORCID: https://orcid.org/0000-0003-4862-1781 \\ Universidade Estadual do Sudoeste da Bahia, Brasil \\ E-mail: emilemiranda@hotmail.com \\ Flavia Pedro dos Anjos Santos \\ ORCID: https://orcid.org/0000-0002-0971-4494 \\ Universidade Estadual do Sudoeste da Bahia, Brasil \\ E-mail: flaviapas7@gmail.com
}

\begin{abstract}
Resumo
O estudo tem como objetivo compreender a percepção de mulheres surdas sobre a comunicação com o profissional enfermeiro no cuidado ao parto. Trata-se de um estudo descritivo, exploratório, de abordagem qualitativa, realizado com nove mulheres surdas. A coleta de dados foi realizada no período de setembro a outubro de 2019, por meio de entrevista semiestruturada em Língua Brasileira de Sinais, mediante a participação de intérprete. Para a análise dos dados foi utilizada a análise de conteúdo, modalidade temática. Das entrevistas emergiram duas categorias: Entraves no cuidado em saúde às parturientes surdas e estratégias de comunicação do enfermeiro durante o parto de mulheres surdas. A percepção de mulheres surdas evidenciou a existência de obstáculos no processo de comunicação do enfermeiro durante o parto, ocasionados pelo desconhecimento sobre a Língua Brasileira de Sinais, inexistência de intérprete no ambiente hospitalar, o acompanhante como interlocutor na comunicação e o uso de máscara. Por sua vez, na tentativa de comunicar-se com a usuária surda, o enfermeiro utilizou gestos, leitura orofacial e a escrita em português; contudo, essas estratégias apresentaram-se bastante limitadas e não demonstraram efetividade para proporcionar uma comunicação de qualidade. Urge a necessidade de valorização, uso e difusão da Língua Brasileira de Sinais na formação e qualificação profissional do enfermeiro, para que ocorra a possibilidade de diálogo, sem interferência de terceiros como interlocutores na comunicação, o que contribuirá significativamente para o desenvolvimento de um cuidado ético e humanizado.
\end{abstract}

Palavras-chave: Comunicação; Surdez; Parto; Enfermagem; Cuidados de enfermagem.

\begin{abstract}
This study aims to understand the perception of deaf women about communication with nurses in childbirth care. This is an descriptive, exploratory study with a qualitative approach, carried out with nine deaf women. Data collection was carried out in the period from September to October 2019, through semi-structured interviews in Brazilian Sign Language, with the participation of an interpreter. For data analysis, the thematic content analysis was used. Two categories emerged from the interviews: barriers to healthcare for deaf women and communication strategies for nurses during the delivery of deaf women. The perception of deaf women evidenced the existence of obstacles in the nurses' communication process during childbirth, caused by the lack of knowledge on the Brazilian Sign Language, the absence of an interpreter in the hospital environment, the companion as interlocutor in communication and the use of masks. In turn, in an attempt to communicate with the deaf user, the nurses used gestures, orofacial reading and writing in Portuguese; however, these strategies were quite limited and have not been effective in providing quality communication. There is an urgent need to value, use and disseminate Brazilian Sign Language in the training and professional qualification of nurses, in order to make the possibility of dialogue happen, without interference from third parties as interlocutors in communication, contributing to the development of an ethical and humanized care.
\end{abstract}

Keywords: Communication; Deafness; Parturition; Nursing; Nursing care.

\section{Resumen}

Este estudio tiene como objetivo comprender la percepción de mujeres sordas sobre la comunicación con el profesional enfermero en el cuidado al parto. Se trata de un estudio descriptivo, exploratorio, de abordaje cualitativo, realizado con nueve mujeres sordas. La colecta de datos fue realizada entre setiembre y octubre de 2019, por medio de una entrevista semiestructurada en Lengua Brasileña de Señales, mediante la participación de un intérprete. Para el análisis de los datos se utilizó el análisis de contenido, modalidad temática. De las entrevistas emergieron dos 
categorías: problemas en el cuidado en salud a las parturientes sordas y estrategias de comunicación del enfermero durante el parto de mujeres sordas. La percepción de mujeres sordas evidenció la existencia de obstáculos en el proceso de comunicación del enfermero durante el parto, ocasionados por el desconocimiento de la Lengua Brasileña de Señales, la inexistencia de intérpretes en el ambiente hospitalario, el acompañante como interlocutor en la comunicación y el uso de máscara. A su vez, en la tentativa de comunicarse con la usuaria sorda, el enfermero utilizó gestos, lectura orofacial y la escritura en portugués; sin embargo, esas estrategias fueron bastante limitadas y no demostraron efectividad para proporcionar una comunicación de calidad. Es necesario valorizar, usar y difundir la Lengua Brasileña de Señales en la formación y cualificación profesional del enfermero, para que el diálogo sea posible, sin interferencias de terceros como interlocutores en la comunicación, contribuyendo significativamente para el desarrollo de un cuidado ético y humanizado.

Palabras clave: Comunicación; Sordera; Parto; Enfermería; Cuidados de enfermería.

\section{Introduçãa}

A comunicação é uma ferramenta primordial e inerente aos seres humanos em suas relações sociais, culturais, políticas e econômicas construídas ao longo da história, podendo ser expressa por meio da linguagem verbal e não verbal. Entretanto, ela só ocorre de forma eficiente quando a mensagem enviada através do interlocutor para o receptor, ou vice-versa, é compreensível e acessível, constituindo-se, portanto, a base das relações humanas (Oliveira, Celino \& Costa, 2015).

Na perspectiva da saúde, a comunicação é compreendida como um instrumento facilitador para especializar e qualificar o cuidado (Rezende et al., 2015). Neste sentido, o uso da escuta sensível, acolhimento, formação de vínculos e ações comunicativas são grandes aliadas para humanizar as práticas dos profissionais de saúde (Oyama, Terceiro \& Parazzi, 2017).

No decorrer da história, os surdos foram privados da comunicação por serem considerados pessoas incapacitadas, com graus severos de déficit cognitivo, inertes e sem perspectiva de futuro. Atualmente, ainda que as barreiras na comunicação permaneçam na sociedade, alguns avanços já foram alcançados pelo movimento da comunidade surda, no sentido de garantir os seus direitos como cidadãos detentores de uma língua, culturas e identidades próprias (Strobel, 2009).

Nessa direção, a Lei 10.436, de 24 de abril de 2002 e o Decreto n. ${ }^{\circ}$ 5.626, de 22 de dezembro de 2005 se configuraram em documentos importantes na garantia dos direitos dos surdos, tendo em vista que reconheceram a Língua Brasileira de Sinais (Libras) como meio legal de comunicação e expressão (Brasil, 2002) e a instituiu como segunda língua oficial do Brasil (Brasil, 2005). Contudo, apesar da implantação dessas medidas, os surdos ainda enfrentam muitos desafios, pois a realidade geralmente não condiz com a legislação vigente (Magrini \& Santos, 2014).

Vale ressaltar que a Libras não são gestos, nem mímica, mas é uma língua de modalidade espaço-visual, que possui sua própria gramática com complexidade linguística equivalente às línguas orais, sendo a língua natural dos surdos e que a partir dela eles têm acesso às informações e compreensão da realidade. Por sua vez, a língua portuguesa se constitui como segunda língua (L2) e por falta de acesso a esta língua, os surdos não a compreendem em sua totalidade.

Assim, uma assistência de qualidade, atrelada a uma comunicação efetiva, possui importância ainda maior no atendimento deste público, que representa uma importante parcela da população brasileira com cerca de 9,7 milhões de pessoas (IBGE, 2015), principalmente porque os enfermeiros, em sua grande maioria, parecem não estar capacitados o suficiente para estabelecer uma comunicação eficaz (Costa et al., 2018).

Nesse sentido, torna-se relevante o desenvolvimento de pesquisas que busquem ampliar a discussão sobre a importância da Libras no processo de comunicação entre enfermeiro e mulheres surdas, no intuito de contribuir para que estas usuárias se sintam acolhidas e incluídas nas práticas de cuidado desenvolvidas pelo enfermeiro durante o parto. Além disso, é pertinente a superação da perspectiva biomédica e curativista, a partir da compreensão da surdez como uma diferença linguística e cultural e não um processo patológico que precisa de intervenções clínicas, cirúrgicas e reabilitadoras. Nessa direção, o estudo tem como objetivo compreender a percepção de mulheres surdas sobre a comunicação com o profissional enfermeiro no cuidado ao parto, que emergiu da seguinte pergunta norteadora: Qual a percepção de mulheres surdas sobre a 
comunicação com o profissional enfermeiro no cuidado ao parto?

\section{Metodologia}

Estudo descritivo, exploratório, de abordagem qualitativa, uma vez que enfatiza as diferentes opiniões sobre o fenômeno analisado, a partir da interpretação de entrevistas realizadas com questões abertas (Pereira et al., 2018).

Nessa perspectiva, as entrevistas foram realizadas com nove mulheres surdas selecionadas a partir dos seguintes critérios de inclusão: ter a Libras como primeira língua e ser pertencente a comunidade surda. No que concerne a critérios de exclusão, foram excluídas mulheres que não tiveram a vivência do parto.

A coleta de dados foi realizada no Núcleo de Ações Inclusivas para pessoas com deficiência de uma universidade localizada no interior do estado da Bahia, no período de setembro a outubro de 2019, por meio de entrevista semiestruturada em Libras, mediante a participação de uma intérprete de Libras.

As questões iniciais foram relacionadas ao perfil sociodemográfico das participantes e de questões norteadoras sobre a percepção de mulheres surdas quanto a comunicação com o profissional enfermeiro durante o parto. O procedimento adotado para coleta dos dados foi a interpretação para Libras do Termo de Consentimento Livre e Esclarecido, com posterior assinatura, seguido da gravação em vídeo das respostas das participantes que foram traduzidas para o português, mediante autorização prévia das mesmas.

No intuito de atender as recomendações da Resolução No 466/2012 essa pesquisa foi submetida ao Comitê de Ética em Pesquisa da Universidade Estadual do Sudoeste da Bahia e aprovada sob parecer $\mathrm{n}^{\circ} 3.233 .713$ e Certificado de Apresentação para Apreciação Ética nº 09441619.0.0000.0055.

As participantes do estudo foram identificadas no texto por um número que correspondeu à ordem crescente de realização das entrevistas, ou seja, entrevistada $\mathrm{n}^{\circ}$ 1, leia-se, E1, e assim sucessivamente. Para a análise dos dados foi utilizada a análise de conteúdo, modalidade temática, composta por três etapas: pré-análise, exploração do material e tratamento dos resultados e interpretação (Bardin, 2011).

A primeira etapa foi caracterizada pela organização dos documentos que seriam utilizados na análise com base no objetivo proposto, contemplando a transcrição de nove entrevistas. Prosseguindo, foi realizada a leitura flutuante do material coletado com a finalidade de se constituir o corpus. A segunda etapa possibilitou a exploração do material com recortes do texto em unidades de categorização e codificação para o registro desses dados. Na terceira etapa, foi realizado o tratamento dos resultados obtidos e sua interpretação, a partir da organização dos resultados em duas categorias.

\section{Resultados}

A faixa etária das participantes da pesquisa variou entre 19 a 38 anos, sendo apenas uma participante com 50 anos. No tocante ao estado civil, quatro eram solteiras, uma casada, três em união estável e uma viúva. Quanto ao tipo de parto, nove foram cesarianas e oito normais, dos quais $82,4 \%$ ocorreram em hospitais públicos e 17,7\% em hospitais privados, sendo que a maioria ocorreu entre os anos de 2008 a 2019.

Em relação ao domínio da língua portuguesa escrita, uma participante referiu possuir bom domínio; uma não sabia e as demais possuíam conhecimento superficial. No que se refere ao nível educacional, seis possuíam ensino fundamental incompleto; uma, médio incompleto e duas, médio completo.

\section{Categoria 1 - Entraves no cuidado em saúde às parturientes surdas}

Todas as participantes do estudo referiram que os enfermeiros não souberam se comunicar através da língua de sinais, apontando a necessidade destes profissionais aprenderem esta língua com fluência e não apenas adquirir conhecimento básico. 
Os enfermeiros não sabem a língua de sinais, eles precisam estudar, fazer cursos, mas muitas vezes eles não querem, não sabem, não estudam (E6).

A enfermeira não sabia a língua de sinais. "E agora? você é surda!" Ela dizia [...] É importante que se esforcem para aprender para que os surdos se sintam felizes e orgulhosos de estarem ali (E3).

É importante que os profissionais aprendam a língua de sinais, começar ainda com o alfabeto, se desenvolver e conseguir fluência (E9).

[...] queremos que eles se tornem como intérpretes e sejam fluentes (E7).

As participantes do estudo também apontaram a inexistência do intérprete durante o parto e ressaltaram a importância da presença deste profissional no ambiente hospitalar.

A presença do intérprete nos setores, no ambiente hospitalar é imprescindível porque a comunicação não acontece [...] eu torço para que isso aconteça [...] (E3). É importante a presença de um intérprete [...] A gente precisa cobrar porque a falta de comunicação é muito difícil (E7).

O estudo também identificou que a dependência de um familiar como acompanhante foi mencionada com frustação por não existir a comunicação direta entre o enfermeiro e a mulher.

Tem coisas que a gente não quer que nossa mãe saiba [...] então, precisava daquele momento em particular com a enfermeira [...] eu ficava triste porque realmente precisava ter a comunicação direta, não queria que ninguém intermediasse a comunicação [...] (E8).

Sempre se comunicavam com minha mãe durante o parto, era muito difícil [...] tudo era direcionado a ela, eu tinha que ter muita paciência (E7).

Porém notou-se que, em outra situação, a presença do familiar significou conforto e segurança, por viabilizar a comunicação, inclusive se surgissem dúvidas. Se eu não tivesse a minha família? Se eu tivesse alguma dúvida? Mas como minha irmã estava por perto, eu fiquei mais segura (E3).

Entretanto, a falta de fluência em língua de sinais por parte do acompanhante também dificultou a comunicação entre o enfermeiro e a mulher:

[...] a comunicação era muito restrita, ela [mãe] esquecia muitos sinais [...] (E3).

[...] Eu pedia pra minha mãe me explicar, mas ela sabe muito pouco de Libras e eu não entendia direito o que estava sendo dito (E7).

Além disso, o uso de máscara foi apontado por uma das participantes como um impasse na comunicação com o enfermeiro por impedir a visualização do rosto e lábios deste profissional, numa tentativa de estabelecer uma comunicação através da leitura orofacial. 
[...] o enfermeiro usava uma máscara que impedia de ver os lábios e eu pedia: "tira, tira a máscara para eu poder responder você! Se eu não estou vendo como eu vou saber o que você está falando? Se tirar a máscara eu vou fazer a leitura labial e entender você" (E1).

\section{Categoria 2 - Estratégias de comunicação do enfermeiro durante o parto de mulheres surdas}

$\mathrm{O}$ estudo apontou que nenhum enfermeiro possuía domínio da Libras, utilizando-se de gestos como estratégia para comunicação:

Os profissionais só usavam gestos durante o parto, mas aquilo não tinha significado nenhum. Não tinha interpretação, não tinha língua de sinais, era muito complicado (E7).

[...] a enfermeira falava: "vou administrar um remédio". E usava gestos, só a partir de gestos e era uma comunicação bem restrita. Eu tinha que usar gestos pra indicar o que eu estava sentindo, foi muito trabalhosa a comunicação (E3).

As participantes também referiram que, na tentativa de comunicar-se com os enfermeiros, utilizaram a leitura labial.

Não existia comunicação. Só via as pessoas oralizando e tentava entender o que estava acontecendo [...] (E7).

[...] Eu conseguia compreender tentando fazer um pouco de leitura labial (E8).

Também foi relatado que a escrita em português foi utilizada como estratégia para se estabelecer uma comunicação eficaz; contudo, a aquisição insuficiente do português na modalidade escrita como L2 propiciou dificuldades para a comunicação com o enfermeiro: Só a língua portuguesa a gente não entende nada, eu não compreendo as palavras (E1).

Na minha opinião é muito difícil o português. Ás vezes a gente sabe bem pouco ou quase nada (E5).

[...] ás vezes tentava pela escrita [...] mas eu não sabia ao certo as palavras, a organização das palavras, eu tentava ler e às vezes ficava em dúvida, não sabia ao certo o que estava sendo dito (E6).

A ausência de comunicação em Libras foi um fator agravante durante a assistência prestada por enfermeiros durante o parto de mulheres surdas. Alguns sentimentos negativos como tristeza, desprezo e angústia foram evocados e diretamente relacionados a falta de comunicação, sendo que a comunicação a partir da Libras foi citada como uma forma de cuidado.

Eu me sentia desprezada, ninguém cuidava de mim, [...] estava sofrendo e não foi algo bom, sem comunicação nenhuma [...] os profissionais diziam: "ah! Ela é surda, deixa ela lá" e eu gritando de dor [...] eu tive o bebê sozinha, ele nasceu sozinho e ficou lá parado, deitado e eu percebia que ele tinha nascido [...] ele quase morria [...] a falta de comunicação deixa a gente muito angustiada, é importante o cuidado em língua de sinais (E4).

Eu fiquei muito angustiada na hora do parto, eu olhava, tentava entender o que as pessoas estavam dizendo [...] ninguém sabia Libras e eu ficava muito angustiada, tinha que ter muita paciência. Eu fico pensando e sentindo realmente como seria se a gente tivesse o cuidado no momento do parto, o carinho, a comunicação em língua de sinais, eu fico imaginando [...] a gente fica pensando nisso como o ideal [...] (E6). 
Na hora do parto eu me sentia triste, me sentia mal, não conseguia me comunicar [...] não teve nada de humanização, não teve nada disso (E9).

\section{Discussão}

A partir dos depoimentos das entrevistadas, foi possível identificar a existência de obstáculos no processo de comunicação entre mulheres surdas e enfermeiros, entre os quais se destaca o despreparo do enfermeiro para atender estas usuárias, por não evidenciar conhecimento sobre a Libras, ocasionando uma comunicação ineficiente, fato que não contribuiu para o cuidado humanizado e qualificado.

Pesquisa realizada em um município de Alagoas, com 20 enfermeiros atuantes nas Unidades Básicas de Saúde, corrobora com os resultados deste estudo, por revelar que todos os profissionais entrevistados não utilizaram a Libras para se comunicar durante a assistência em saúde à usuários surdos (Soares et al., 2018).

Outra pesquisa que objetivou descrever as dificuldades encontradas por usuários surdos na assistência à saúde, demonstrou que a principal barreira é a comunicacional, em virtude do déficit no nível de conhecimento dos profissionais de saúde em relação a língua de sinais. Além disso, também foram identificadas como dificuldades a ausência de intérprete nas instituições de saúde, a falta de paciência dos profissionais que atendiam nos serviços de saúde, a discriminação e os estereótipos (Silva et al., 2021).

Considerando que a Libras é a língua natural dos surdos, e que por meio dela eles reafirmam sua identidade e se conectam com mundo exterior, torna-se indispensável que os enfermeiros a conheçam para garantir uma assistência integral e que suas práticas sejam realizadas por meio de um processo comunicativo bem estabelecido.

Nessa direção, é primordial que durante a formação do enfermeiro seja ministrada disciplina, em caráter obrigatório, que aborde a Libras, tendo em vista que se for ofertada na modalidade optativa nem todos acadêmicos de enfermagem terão contato com a mesma durante a graduação.

Entretanto, por se tratar de uma língua, a carga horária de uma disciplina não é o suficiente para garantir a fluência, mas pode suscitar discussões importantes sobre a relevância da Libras para as práticas de cuidado, de forma a sensibilizar o futuro enfermeiro a se inserir em cursos mais aprofundados que lhe assegure a fluência dessa língua.

Convém ressaltar que a fluência em língua de sinais, por vezes, se desenvolve de forma lenta e gradual, porém o fato do enfermeiro não ter conhecimento sobre a Libras não o isenta da responsabilidade de assegurar os direitos dos usuários surdos, no sentido de acionar órgãos competentes como, por exemplo, a central de intérpretes, para disponibilizar profissionais capacitados em situações que o enfermeiro não consegue estabelecer uma comunicação efetiva, por meio dessa língua.

No Brasil, a presença do intérprete de línguas de sinais no cenário hospitalar é prevista na Norma Brasileira 15599/08 e determina que instituições de assistência à saúde devem "prover atendimento com apoio de intérprete de Libras e guia intérprete para surdo-cegos, em consultas, internações e atendimento de emergência por convênio, plantão ou meios eletrônicos" (ABNT, 2008, p. 12). Ademais, a Lei $n^{\circ}$ 10.436/2002 também prevê a garantia de atendimento e tratamento adequado aos usuários surdos por parte de instituições públicas e empresas privadas que são conveniadas ao serviço público (Brasil, 2002).

Considerando a relevância da capacitação dos profissionais da área da saúde no atendimento a usuários surdos em ambientes hospitalares, os gestores devem se comprometer a inserir programas de educação continuada, além de oferecer cursos de Libras, em conformidade ao inciso X, do artigo $25^{\circ}$ do Decreto 5.626/05, que garante o apoio à capacitação e formação de profissionais da rede de serviços do Sistema Único de Saúde (SUS) quanto ao uso de Libras e sua tradução e interpretação (Brasil, 2005).

Destaca-se ainda que o enfermeiro ao acompanhar o pré-natal de gestantes surdas, deve buscar a articulação dos 
diferentes níveis de atenção à saúde, de forma a organizar o fluxo e viabilizar o acesso a informações importantes sobre as especificidades de gestantes surdas, além de reforçar sobre a necessidade de um intérprete no momento do parto, de modo a propiciar que o serviço consiga se organizar para melhor atender a demanda dessa usuária.

Tal perspectiva é assegurada por meio da Lei Brasileira de Inclusão da Pessoa com Deficiência que estabelece a remoção de toda e qualquer barreira arquitetônica, de ambientação e de comunicação, com a finalidade de atender as especificidades das pessoas com deficiência sensorial, física, intelectual e mental bem como garantir o acesso a todas as formas de comunicação nos serviços de saúde públicos e privados, inclusive por meio da Libras (Brasil, 2015).

No entanto, quando a lei não é cumprida o cuidado à saúde do surdo é prejudicada de tal modo, que eles se veem privados deste atendimento em saúde (Oliveira, Celino \& Costa, 2015) sendo necessário que serviços de saúde e profissionais atuem conjuntamente, com o propósito de assegurar os direitos dessa população.

No estudo foi evidenciado que apesar da presença do acompanhante gerar um conforto e ser importante no processo de comunicação entre o enfermeiro e usuária surda, podem ocorrer prejuízos na autonomia destas usuárias em virtude de não responder por si mesmo e da violação da sua privacidade. Uma pesquisa apontou que a presença de uma terceira pessoa no cuidado à usuários surdos pode limitar sua individualidade e oportunidade de expor seus anseios bem como fragilizar a construção da confiança, por não possibilitar que este usuário se envolva ativamente no diálogo, o que poderá levá-lo a omitir informações importantes sobre sua saúde, por constrangimento ou vergonha (Soares et al., 2018).

Ademais, foi revelado pelas participantes do estudo que a falta de fluência em língua de sinais por parte dos acompanhantes, ocasionou ruídos na sua comunicação com o enfermeiro e distorceu o real sentido da mensagem. Entretanto, mesmo que os acompanhantes consigam se comunicar a partir da Libras, não necessariamente desempenham o papel de intérpretes, tendo em vista que para atuar como mediadores na comunicação precisam ser qualificados, de maneira a interferir o mínimo possível no processo comunicativo (Quadros \& Karnopp, 2004).

Por sua vez, a leitura orofacial se configurou em uma estratégia utilizada para estabelecer a comunicação com o enfermeiro, sendo reforçada a importância deste profissional não cobrir a face com máscaras cirúrgicas durante o diálogo. Todavia, a pandemia por COVID-19 é uma nova realidade sanitária, na qual o uso de equipamento de proteção individual, especialmente de máscaras, durante o cuidado à saúde, tornou-se extremamente necessária (Peres, Boléo-Tomé \& Santos, 2020), fato que dificulta a possibilidade da leitura labial, referida como estratégia comunicativa utilizada por surdas para estabelecer a comunicação com o enfermeiro.

Diante do exposto, torna-se necessário reforçar a necessidade dos profissionais aprenderem a Libras, além de criarem estratégias como o uso de máscaras transparentes, com os lábios a mostra, para facilitar a comunicação entre ambos. $\mathrm{O}$ estudo também apontou que os enfermeiros utilizaram predominantemente gestos, seguido do auxílio de acompanhantes, leitura orofacial e a escrita em português, como estratégias para efetivar a comunicação durante o parto de mulheres surdas. Dados semelhantes foram encontrados em uma pesquisa sobre estratégias de comunicação utilizadas por enfermeiros no cuidado a usuários surdos, dos quais 46,15\% relataram o uso dos gestos; 15,38\% fizeram uso da leitura labial; 30,77\% utilização da escrita; 3,85\% recorreram ao desenho; e 3,85\% tiveram o auxílio do intérprete de Libras (Machado et al., 2013).

Pensar a língua de sinais como pantomima, ou seja, uma representação da realidade exclusivamente através de gestos, mímicas ou expressões corporais, é um mito. Essa percepção equivocada impede a compreensão da língua de sinais como uma língua propriamente dita, composta por sistemas linguísticos, com o nível sintático, semântico, morfológico, fonológico e pragmático, independente do português e que permite o diálogo de conceitos abstratos.

Desta maneira, a comunicação por meio de gestos é restrita e não deve ser utilizada como estratégia para tentar se comunicar com usuários surdos (Gesser, 2009). Existe uma forte crença popular que os surdos sabem fazer leitura labial, porém para aprimorar tal habilidade são necessárias horas exaustivas e extenuantes de treinamentos fono-articulatórios, que 
nem sempre são satisfatórios, pois essa habilidade não é adquirida de maneira natural (Gesser, 2009).

Vale ressaltar que as políticas públicas relacionadas à saúde auditiva no país, em todos os níveis de complexidade, ainda persistem em práticas reabilitadoras, com predomínio da visão curativista e biomédica. Há uma ênfase na oferta e ampliação da cobertura dos procedimentos diagnósticos para detecção precoce da surdez, numa tentativa de corrigi-la, com o intuito de inserir os surdos na sociedade ouvinte, através da terapia fonoaudiológica e oferta de próteses auditivas (Mazzarotto et al., 2019; Silva, Gonçalves \& Soares, 2014).

A triagem auditiva neonatal também é considerada uma estratégia para o diagnóstico precoce da surdez em neonatos e lactentes, mais um exemplo que reforça a perspectiva atual, preocupada em apenas tratar de forma clínica e cirúrgica o indivíduo, além de reabilitá-lo para viver em sociedade e alcançar "padrões mais elevados de qualidade de vida", excluindo totalmente outras possibilidades, ampliadas através do uso da Libras (Rodrigues et al., 2015).

Nesse contexto, onde o uso e difusão da Libras não é uma prioridade e a língua portuguesa continua sendo uma das estratégias frequentemente utilizada pelos profissionais de saúde, foi possível identificar, através dos relatos das participantes desta pesquisa, a dificuldade na compreensão da mesma pelas parturientes, principalmente pela dificuldade de acesso à educação de qualidade.

Nessa direção, o Decreto 5.626/05 prevê que o acesso à educação é um direito do surdo, devendo ser ofertado de forma obrigatória, sendo o ensino da língua de sinais como primeira língua (L1) e o português na modalidade escrita como L2 (Brasil, 2005). Além disso, em decorrência do déficit na educação promovida pelas escolas, que não trabalham na perspectiva bilíngue, os surdos apresentam sérias dificuldades na leitura e escrita da língua portuguesa (Quadros \& Schmiedt, 2006).

Tais circunstâncias denotam que a capacidade de compreender o mundo linguístico, cultural e social dos surdos perpassa pelo processo de educação permanente em saúde, no intuito de potencializar a comunicação e o cuidado produzido pelo enfermeiro com o usuário surdo, por meio da fluência da língua de sinais. Assim, compreende-se que a humanização do cuidado em saúde está inter-relacionada com a comunicação, sendo um alicerce que deverá ser construído a partir da relação estabelecida entre enfermeiros e mulheres surdas, através de um processo comunicativo bem estabelecido no qual o usuário do serviço de saúde compartilha sentimentos e expectativas, de modo a facilitar a identificação e resolução de problemas (Pott et al., 2013).

Dessa forma, os profissionais devem utilizar a comunicação como uma estratégia de humanização do cuidado de enfermagem, esclarecendo acerca dos procedimentos e exames a serem realizados, rotinas e normas da instituição, com a finalidade de reduzir o sofrimento e ansiedade durante o parto. Uma pesquisa que se propôs a estudar a percepção de mulheres surdas quanto aos cuidados de enfermagem durante a gestação, parto e puerpério, trouxe resultados similares, ao identificar que a comunicação além de ser ignorada, se constituiu a maior dificuldade enfrentada pela equipe de enfermagem (Costa et al., 2018).

Assim, durante o cuidado ao parto é necessário que ocorra uma comunicação efetiva entre enfermeiro e mulher, a fim de facilitar a compreensão dos procedimentos realizados em seu corpo, além de encorajar a sua participação no processo parturitivo, reduzir medos, anseios e lhe proporcionar segurança (Costa et al., 2018). Tais perspectivas são benéficas e contribuem para proporcionar o cuidado integral, com o objetivo de permitir que a mulher vivencie o nascimento de um filho de forma positiva e singular (Silva et al., 2016).

Portanto, depreende-se que sem a comunicação em língua de sinais dificilmente o enfermeiro conseguirá desenvolver uma assistência à usuárias surdas, baseada na humanização e na construção de vínculo e menos ainda minimizar os anseios e medos das mesmas durante o parto, a fim de que possam vivenciar o parto com dignidade, acolhimento e respeito. 


\section{Conclusão}

Evidenciou-se a partir deste estudo a existência de obstáculos no processo de comunicação do enfermeiro durante o parto, ocasionados pelo desconhecimento deste profissional sobre a Libras, inexistência de intérprete no ambiente hospitalar, o acompanhante como interlocutor na comunicação e o uso de máscara.

Na tentativa de comunicar-se com a usuária surda, o enfermeiro utilizou-se de gestos, do auxílio de acompanhantes, da leitura orofacial e da escrita em português; estratégias estas que se apresentaram bastante limitadas e não demonstraram efetividade para proporcionar qualidade na comunicação.

Tais achados apontam a premente necessidade de valorização, uso e difusão da Libras na formação e qualificação profissional do enfermeiro, para que ocorra a possibilidade de diálogo, sem interferência de terceiros como interlocutores na comunicação, o que contribuirá significativamente para o desenvolvimento de um cuidado ético e humanizado.

Considera-se que enquanto não houver mudança no atual cenário das políticas públicas em saúde auditiva e na formação do enfermeiro, mulheres surdas continuarão sendo privadas dos seus direitos, fato que diverge dos princípios do SUS, especialmente referente ao direito à informação sobre a sua saúde durante o cuidado prestado pelos profissionais. Ademais, os gestores devem estabelecer estratégias que visem a capacitação dos enfermeiros com ênfase na comunicação em Libras.

No âmbito científico ainda são incipientes os estudos que retratam a perspectiva da mulher surda, visto que a maioria traz o olhar do profissional de saúde ou do familiar sobre o cuidado prestado, o que sinaliza a necessidade de ampliar as pesquisas que dão voz à população que está sendo assistida.

Vale ressaltar ainda a relevância da realização de estudos que propiciem reflexões sobre a comunicação entre enfermeiros e mulheres surdas para além da assistência intraparto, de forma a abranger o pré-natal, pré e pós-parto, pois durante todo o ciclo gravídico puerperal, as mulheres continuam enfrentando dificuldades de comunicação que refletem na qualidade do cuidado em saúde.

Este estudo apresenta limitações por revelar as percepções de mulheres surdas de um município do interior da Bahia, não permitindo generalizações para outros cenários e indicando a permanência de se realizar futuras pesquisas, com ênfase na ótica de pessoas que vivenciam a surdez.

\section{Referências}

Associação Brasileira de Normas e Técnicas (2008). NBR 15599: acessibilidade - comunicação na prestação de serviços. ABNT. https://portalarquivos2.saude.gov.br/images/sismob2/pdf/field_generico_imagens-filefield-description_21.pdf

Bardin L. (2011). Análise de conteúdo. Edições 70.

Brasil. (2002). Lei no 10.436, de 24 de abril de 2002. Dispõe sobre a Língua Brasileira de Sinais - LIBRAS e dá outras providências. Presidência da República. Casa Civil. http://www.planalto.gov.br/ccivil_03/leis/2002/110436.htm Brasil. (2005). Presidência da República. Casa Civil. Decreto n5.626, de 22 de dezembro de 2005. Regulamenta a Lei n ${ }^{\circ} 10.436$, de 24 de abril de 2002, que dispõe sobre a Língua Brasileira de Sinais - Libras, e o art. 18 da Lei no 10.098, de 19 de dezembro de 2000. http://www.planalto.gov.br/ccivil_03/_ato2004-2006/2005/decreto/d5626.htm

Brasil. (2015). Presidência da República. Casa Civil. Lei n ${ }^{\circ} 13.146$, de 6 de julho de 2015. Institui a Lei Brasileira de Inclusão da Pessoa com Deficiência. Estatuto da Pessoa com Deficiência. Brasília: Diário Oficial da União. http://www.planalto.gov.br/ccivil_03/_ato2015-2018/2015/lei/113146.htm

Costa, A. A., Vogt, S. E., Ruas, E. D. F. G., Holzmann, A. P. F. \& Silva, P. L. N. D. (2018). Acolher e escutar o silêncio: o cuidado de enfermagem sob a ótica da mulher surda durante a gestação, parto e puerpério. Rev. Pesqui, 10(1), 123-129. http://dx.doi.org/10.9789/2175-5361.rpcfo.v10.5997

Gesser A. (2009). LIBRAS? Que língua é essa? Crenças e preconceitos em torno da língua de sinais e da realidade surda. São Paulo: Parábola Editorial.

Instituto Brasileiro de Geografia e Estatística (2015). Censo Demográfico 2010. IBGE. https://www.ibge.gov.br/

Machado, W. C. A., Machado, D. A., Figueiredo, N. M. A., Tonini, T., Miranda, R. S. \& Oliveira G. M. B. (2013). Língua de sinais: como a equipe de enfermagem interage para cuidar de clientes surdos? Rev. Pesqui, 5(3), 283-292. https://pesquisa.bvsalud.org/portal/resource/pt/lil-683564

Magrini, A. M. \& Santos, T. M. M. (2014). Comunicação entre funcionários de uma unidade de saúde e pacientes surdos: um problema? Distúrbios de comunicação, 26(3), 550-8. 
Research, Society and Development, v. 10, n. 3, e41710313575, 2021

(CC BY 4.0) | ISSN 2525-3409 | DOI: http://dx.doi.org/10.33448/rsd-v10i3.13575

Mazzarotto, I. H. E. K., Gonçalves, C. G. D. O., Bellia, C. G. D. L., Moretti, C. A. M. \& Iantas, M. R. (2019). Integralidade do cuidado na atenção à saúde auditiva do adulto no SUS: acesso à reabilitação. Audiology-Communication Research, 24. https://doi.org/10.1590/2317-6431-2018-2009

Ministério da Saúde, Brasil. (2012). Conselho Nacional de Saúde. Resolução no 466, de 12 de dezembro de 2012. Brasília: Minis tério da Saúde.

Oliveira, Y. C. A. D., Celino, S. D. D. M. \& Costa, G. M. C. (2015). Comunicação como ferramenta essencial para assistência à saúde dos surdos. Physis: revista de saúde coletiva, 25(1), 307-320. https://doi.org/10.1590/S0103-73312015000100017

Oyama, S. M. R., Terceiro, F. A. B. M. \& Parazzi, L.C. (2017). Comunicação do enfermeiro docente na assistência a pessoas cegas e surdas. CuidArte, Enferm, 11(1), 78-85. https://pesquisa.bvsalud.org/portal/resource/pt/bde-31628

Pereira A. S., Shitsuka, D. M., Parreira, F. J., \& Shitsuka, R. (2018). Metodologia da pesquisa científica. UFSM. https://repositorio.ufsm.br/bitstream/handle/1/15824/Lic_Computacao_Metodologia-Pesquisa-Cientifica.pdf?sequence=1

Peres, D., Boléo-Tomé, J. P. \& Santos, G. (2020). Proteção Facial e Respiratória: Perspetivas Atuais no Contexto da Pandemia por COVID-19. Acta Médica Portuguesa, 33(13), 583-92. https://doi.org/10.20344/amp.14108

Pott, F. S., Stahlhoefer, T., Felix, J. V. C. \& Meier, M. J. (2013). Medidas de conforto e comunicação nas ações de cuidado de enfermagem ao paciente crítico. Rev. bras. enferm, 66(2), 174-179. https://doi.org/10.1590/S0034-71672013000200004

Quadros, R. M. \& Karnopp, L. B. (2004). Língua Brasileira de Sinais: estudos linguísticos. Artmed.

Quadros, R. M. \& Schmiedt, M. L. P. (2006). Ideias para ensinar português para alunos surdos. MEC, SEESP.

Rezende, R. D. C. D., Oliveira, R. M. P. D., Araújo, S. T. C. D., Guimarães, T. C. F., Santo, F. H. D. E., \& Porto, I. S. (2015). Expressões corporais no cuidado: uma contribuição à Comunicação da Enfermagem. Revista Brasileira de Enfermagem, 68(3), 490-496. https://doi.org/10.1590/0034$7167.2015680316 \mathrm{i}$

Rodrigues, G. R. I., Loiola-Barreiro, C. M., Pereira, T., \& Pomilio, M. C. A. (2015). A triagem auditiva neonatal antecipa o diagnóstico e a intervenção em crianças com perda auditiva? Audiology-Communication Research, 20(3), 246-254. https://doi.org/10.1590/S2317-64312015000200001453

Silva, L. S. G. D., Gonçalves, C. G. D. O., \& Soares, V. M. N. (2014). Política Nacional de Atenção à Saúde Auditiva: um estu do avaliativo a partir da cobertura de serviços e procedimentos diagnósticos. CoDAS, 26(3), 241-7. https://doi.org/10.1590/2317-1782/201420140440

Silva, M. de L., Silva, M. P. B., Leite, A. C., Melo, B. C., Santos, A. B. A. de S., Moura, L. C. de, Sobrinho, W. D., Santos, A. G., Moraes, R. dos S., Araujo, G. B., Amorim, A. P., Apolinário, J. M. dos S. S., \& Fagundes, G. R. S. (2021). As dificuldades encontradas na assistência à saúde às pessoas com surdez. Research, Society and Development, 10(2), e38910212372. https://doi.org/10.33448/rsd-v10i2.12372

Silva, Ú., Fernandes, B. M., Paes, M. S. L., Souza, M. D. D., \& Duque, D. A. A. (2016). O cuidado de enfermagem vivenciado por mulheres durante o parto na perspectiva da humanização. Rev. enferm. UFPE on line, 10(4), 1273-1279. https://doi.org/10.5205/1981-8963-v10i4a11113p1273-1279-2016

Soares, I. P., de Lima, E. M. M., dos Santos, A. C. M., \& Ferreira, C. B. (2018). Como eu falo com você? a comunicação do enfermeiro com o usuário surdo. Revista Baiana de Enfermagem, 32.

Strobel, K. (2009). História da educação de surdos. Florianópolis: UFSC. https://www.libras.ufsc.br/colecaoLetrasLibras/eixoFormacaoEspecifica/hi storiaDaEducacaoDeSurdos/assets/258/TextoBase_HistoriaEducacaoSurdos.pdf 